\title{
Multicultural Team Management in the Context of a Development Work
}

\author{
Molla Mekonnen Alemu ${ }^{1}$ \\ ${ }^{1}$ United Nations Development Programme, Freetown, Sierra Leone \\ Correspondence: Molla Mekonnen Alemu, Wilkinson 55, Freetown, Sierra Leone. Tel: 232-7906-1001. E-mail: \\ mollamekonnen@gmail.com
}

Received: August 13, 2015 Accepted: October 19, 2015 Online Published: December 4, 2015

doi:10.5539/jsd.v9n1p8 URL: http://dx.doi.org/10.5539/jsd.v9n1p8

\begin{abstract}
Diverse teams have become common practice in today's world. The current trend of globalization is making managers to work in a diverse multicultural team set up whereby the diversified team members will come up with a new set of skills, ideas, approaches, etc. to the team. It has however, its own challenges in harmonizing the contribution of the culturally diverse team members. Cross-cultural differences in a development work context also entail a range of issues varying from individuals cultural background, characteristics on work places, to their own values and ways of doing things which will have a its own influence on their working style, interactions and relationships at work places. Communication styles, language, a person's cultural background, and perceptions on conflict, styles and methods of doing the work as well as the style of decision making will have an impact how individuals will act and behave in work places. Therefore, the question will be how a manager can successfully lead and work in a culturally diverse team. This study was conducted in Sierra Leone which was aimed at identifying the major bottlenecks of multicultural team management and come up with workable tips for working within a multicultural setting development work.
\end{abstract}

Keywords: multicultural, team, management

\section{Introduction}

The present day work environments have moved away from the monochromic office set-ups to the one that is decorated by members of a team gathered from different parts of the globe. The current trend of globalization is making managers to work in a diverse multicultural team set up whereby the diversified team members will come up with a new set of skills, ideas, approaches, etc. to the team. It has however, its own challenges in harmonizing the contribution of the culturally diverse teams whereby members of a team are impacted by diverse cultural issues: ethnic, organizational as well as nationality (Chad, 2006).

The widely used characterization of cultural diversity include racial, sexual, organizational, professional, and national heterogeneity. Cultural diversity is here defined as heterogeneity of national cultures of team members; whereby an individual's national culture is considered to be that of his or her country of residence. Culture has been defined as "the collective programming of the mind which distinguishes the members of one group or category of people from another". Two important frameworks of cultural dimensions are those of Hall and Hofstede. These define culture according to a small number of dimensions, in which each culture varies, but neither of the frameworks seems sufficient to capture the complexity of culture

(Hall, 1983; Hofstede, 1991; Pnina, 2008). According to Guirdham (1999), diversity also denotes to people from various groups such as gender, religious groups, younger and older groups of people, ethnicity and nationality etc.

Pauline (2010) mentioned that, while reconnoitering the definition of working under a culturally diversified team from the lenses of efficiency of a team, pros and cons; different literatures recommends as multicultural team set-up is reasonably a multifaceted matter to evaluate. Overall, in terms of productivity and efficiency heterogeneous teams do have a grander capacity than teams which are homogenous, nevertheless heterogeneous teams are not free from manifold challenges. This contradicting testimonial is clear as Adler (2008) states that "multicultural teams thus have the potential to achieve higher productivity than homogenous teams, but they also risk experiencing greater losses due to faulty process". It is also a vivid fact that the efficiency of a diversified 
team can be affected negatively as a result of the faulty processes (Pauline, 2010).

Culturally diversified teams are different. Apart from culture, members of the team to need to contemplate issues like; the drive of the team existence, the impact of variations on personal behaviors, cultural background, variations on professional values, prominence for emotional intelligence, and the important part of the support giving systems and functions. Thus, people on leadership role needs to have an up to date core global level competency which they may not have cultured in professional institutes (Jack, 2013).

Managing a culturally diversified team can at times create exasperating management quandaries. More specifically, differences in the cultural set up can cause a significant challenge to a productive teamwork as it may not be easy to diagnose its effect unless the damage is significantly noticed. The greatest test of leading multicultural teams is how to spot out the fundamental cultural grounds of the conflict, and to mediate and manage complexities so that the team can get back to normal without having a disastrous effect on the productivity as well as creating the enabling environment for the team to deal with such challenges by themselves in the future. It is however, a general truth that managing cultural obstacles could be an easily achievable if managers and team members are willing to address the cultural barriers without imposing a culturally biased approach on one another (Jeanne et al., 2006). If multicultural issues are not addressed properly, the cultural diversity in work places can be a cause to dismantle and weaken the productivity of organizations by weakening the performance of team members (Ahu et al., 2006). As Adler (1986) puts it, 'Only if well managed can culturally diverse groups hope to achieve their potential productivity (cited in Ahu et al., 2006).'

The issue here comes on how leaders can work efficiently within a multicultural team by exhibiting attentiveness to cultural diversity and values whilst creating the enabling system and framework for the success of the team. Amongst others effective communication skills will play in creating efficient multicultural team (Chad, 2006). Sound management system also helps leaders to develop a committed team spirit in the organization, identifying the gaps and working on capacity development of the staff will also help to improve the productivity of the team by recognizing the values of multiculturalism (ICSC, 2001).

\section{Objectives of the Study}

The study investigated the main challenges that affect a multicultural team in a development work context and have carried extensive literature review on the required skills to work in a multicultural set up.

\section{Research Methodology}

The research was carried out by making use of qualitative data collection techniques as it is a source of well-informed, ironic clarification and descriptions of practices happening in a specific localized settings. By making use of qualitative explorations one can assess different cases and come up with a successful explanations. Qualitative techniques comfort researchers to go beyond primary presumptions as well as structures. As a final point, the results of qualitative studies have an eminence of "undeniability," as Smith (1978) described it (Miles and Huberman, 1984).

Questionnaires were attended by different humanitarian development workers (NGOs), government officials and other development workers in Sierra Leone so as to identify the major challenges of working in a multicultural set-up and to identify the coping strategies being used by the staff. Some were also interviewed. A literature review was also carried out on the subject matter. A total of 47 employees participated in the data collection. The collected data was analysed by making use of data reduction and data display methods.

Data reduction is the process of selecting, focusing, simplifying, abstracting, and transforming the 'raw' data that appear in written-up field notes. Data reduction occurs continuously throughout the life of any qualitatively oriented project. This is part of data analysis. The second major flow of analysis activity is data display. A 'display' is an organized assembly of information that permits conclusion drawing and action taking. The most frequent form of display for qualitative data has been narrative text (Miles and Huberman, 1984).

\section{Results and Discussion}

The present day drifts the modern business world are greatly connected with the incessant modernization and globalization of the economy. Such moves are compounded with a greater quantity of cross border companies, solid competitions of the economy at a global level, and an ever growing divergence within the workforce. These factors are forcing for the creation of a highly competitive business environment and transaction which in turn demands managers to be challenged as they have to work under a multicultural system and set up.

Culturally diversified teams will come up with a new set of skills, ideas, approaches, etc. to the team. It has however, its own challenges in harmonizing the contribution of the culturally diverse teams whereby members of 
a team are impacted by diverse cultural issues that will also bring different understandings and expectations regarding group dynamics and communication (Chad, 2006; Paulina, 2010).

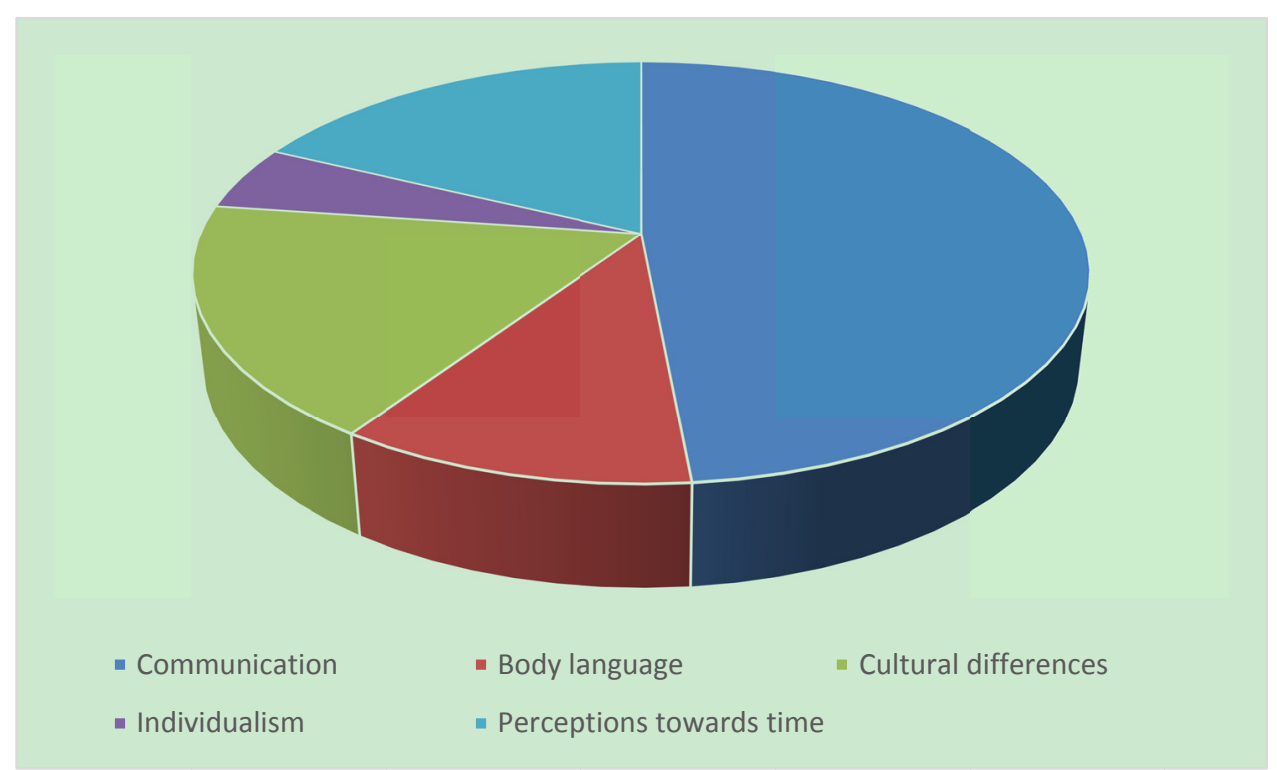

Figure 1. Graphical analysis of the main challenges of multicultural team work

Participants of the study reported that communication is the major problem while working under multicultural team. More specifically lack of clarity and accuracy can result in back and forth communications and hence paves the way for misunderstanding and wastage of resources like time. Body languages are also mentioned as a challenge in smooth communication as something acts which are normal to one culture may be perceived differently/negatively by the other. Different people also value the chains of a work process differently as some will give a strong value to routines while others to regulations or to formalities wherein team members are usually comfortable in taking the dimensions according to their values and experiences than focusing on unusual processes. In a multicultural team, as members are coming from different set up and background, individualism than collective action can prevail in many circumstances since people at times prefer to signify on individual achievement and the desire to gaze after oneself. Due to differences in values across cultures, making decisions can always be impacted negatively. Some in the team may like to have ample evidence as well as the will of the entire team to decide on minor issues while others are waiting for a quick solution. Perceptions towards time as well as appointment is also pointed out as a challenge in coordinating a diversified team.

\section{Multicultural Team Management Skills}

The approach to manage a multicultural teamwork can start by first assisting members of the team to evaluate the values, beliefs and assumptions of their own native culture ahead of the attempt to analyze a different culture. Then team members can rapidly analyze how geographical locations, ancient history and religious factors and norms will mold how people will behave and act in a multicultural setting. This will enable them to have a proper understanding and picture of own traditions and values and when this is done it will enable them to see the different aspects of convergence as well divergence with the rest of the cultures embodied in the group. The rationale is to analyze, appreciate and recognize the differences. It is only then can the team begin to "reconcile the dilemmas" - as advocated by Trompenaars - which can ascend from the clatter of cultural variances. The issue here comes on how leaders can work efficiently within a multicultural team by exhibiting attentiveness to cultural diversity and values whilst creating the enabling system and framework for the success of the team (Jack, 2013; Chad, 2006).

Different approaches can assist in creating efficient and productive multicultural team:

\section{1) Communication Skills}

One of the most important tools that can create a good multicultural team is a noble communication skills. One may ask why it is considered as a paramount importance. Briefly, because it is forever! If something is communicated, there is still a possibility of qualifying it, and modify the context, but it is impossible to undo it. Communication skills are so important since it is also instrumental in laying the foundation of a smooth and 
strong working atmosphere and relationships (Chad, 2006). We need to think about what we are going to say, how are our words going to be perceived? Will the message go through as per the intention? Contemplate on former communications which you have had with others you are about to communicate with. Has there been any special issues on their desired way of communication? For instance, do they prefer communicating pleasantries or will they hammer the head of the nail right away? There is no need of modifying your way of communication to please others, but some level of space to accommodate others way and style of communication will help to develop commendable relationships while working in a culturally diversified team (Michele, 2004; Pnina, 2008).

\section{2) Awareness of Diversity}

We all are different in many ways and thereof awareness of diversity in a multicultural setting is a vital way of having a good work environment. It is also essential to recognize that differences among team members may not necessarily emanate from cultural background, race, age, gender, educational status, etc. it is however, important for leaders to observe and acknowledge the cultural diversity in their group as that will offer an influential means in managing different diversity related complexities (Chad, 2006b).

It is also advisable to share your own cultural backgrounds and values with others while working in a multicultural team as that will help for other team members to get familiar about your background. For instance, it is good for other people to know certain customs, important holidays as well as religious days by being open to queries which may arise from colleagues (Michele, 2004; Joan, 2004; Paulina, 2010).

\section{3) Strong Leadership}

Strong professional leaders can be effective in establishing a fruitful multicultural teams as they will always lead by being example. It is also an important element for the success of any project.

Leaders must have core capability and competencies to analyze the dynamics and challenges of a culturally diverse team. Leaders must be able to foresee conflicts among team members and whenever it occurs, the leader must be able to manage professionally (Chad, 2006b).

Empowering the team members in decision making exercises of the organization and encouraging members to improve and work on their management skills will also help leaders to share work burdens among the group which will help to leverage the productivity of the organization. Leaders should also build trust in the team by going beyond limitations and work related protocols. Good listening habit and treating others with honor and respect can let the leader to be more efficient in developing a smooth work relationships (ICSC, 2001; Paulina, 2010).

\section{4) Avoid Making Assumptions}

It is always easy to make assumptions which can at times be misleading in building a good work relationships. Therefore, it is advisable to get to know actual facts and truths by finding out the right information.

We all embrace presumptions and we all hold stereotypes; the imperative mechanism is to not permit them impact our behavior. We have to be aware of our preconceptions and is always good to consider them as hypotheses, not as facts at all. Your instinct may have been right on the previous nine instances, however that shouldn't confirm to be correct this time around. Even though, you may be able to know as you have enough evidence with an individual it is impossible to conclude as we all share the interest and opinion of others (Michele, 2004).

\section{5) Equal Treatment and Build on People's Strengths}

Leaders should treat team members with honor and respect. It is also not advisable to treat all members in one or same standard. A leader should target to treat each member as an individual who has his/her own values and backgrounds. Strengths and growth areas are all common in everyone. The benefit of a diversified team is that people will come up with diverse strengths and experience which can easily be tapped for the productivity of the organization.

Recognizing and paying attention to the strengths of team and make the most out of their career by strengthening a shared scheme culture as well by offering them openings to capitalize on their experience, will help leaders in achieving the intended mission and objectives of an agency (Michele, 2004; ICSC, 2001).

\section{6) Building Strong Relationships}

Whenever one embarks in to a new culturally diversified international team, it is always advisable to find opportunities to talk to the different people as that will give the opportunity of getting to know each other and build friendships and relationships. Initially, it may appear as a waste of time, however it could serve a lot as it is 
helpful to develop better understandings at latter stages.

Among other the discussion points could include:

- The preference in the ways of communication (e-mail, phone) and their preferred time of communications

- Knowing the names which individuals prefer to be called

- Working styles (some do enjoy working independently on a specific project? Do members consult others in decision making process?)

- Experience sharing while working in that specific organization

- Getting the name of people right needs also to be considered. Take time to get the pronunciation and spelling of names in the right way (Christine, 2002; Jeanne et al, 2006; Michele, 2004).

\section{Conclusion}

The working environment impacts the effectiveness, morale, productivity and engagement of a team. Multicultural teams are often considered as a positive force leading to effective functioning of an organization whereby the diversified team members will come up with a new set of skills, ideas, approaches, etc. to the team. The challenge, however, is that they will also bring different understandings and expectations regarding group dynamics and communication.

Effective communication skills, awareness of diversity and treating members equally by building relationships among the team are some of the skills which can help to minimize the challenges of working in a multicultural team while making use of the added values that a culturally diversified team can offer. Organizations have to also prepare their staff to work within a multicultural team setting by providing training and team development opportunities.

\section{References}

Adler, N. J. (2008). International Dimensions of Organizational Behavior. Mason, OH: Thomson.

Ahu Tatli, et al. (2006). Managing Diversity. Measuring Success. Chartered Institute of Personnel and Development. 151 The Broadway London SW19 1JQ.

Brett, J., Behfar, K., \& Kern, M. C. (2006). Managing Multicultural Teams. Harvard business review.

Deeks, M. (2004). Cross-cultural team working within The Cochrane Collaboration. Pearnkandola, Version 1.0.

Doerr, J. C. (2004). Dealing with Cross-cultural Conflict in a Multicultural Organization: An Education Management Perspective. Submitted in part fulfilment of the requirements for the degree of Master of Education Management, University of South Africa.

Dylkiewicz, P. K. (2010). The Productivity of Multicultural Teams. What is the influence of national cultural diversity? Bachelor Thesis. Aarhus School of Business, Aarhus University.

Flannes, S. (2004). Effective People Skills for the Project Manager: A Requirement for Project Success and Career Advancement, Flannes Associates, Oakland, CA USA Montréal, Canada.

Grantham, C. (2000). The Future of Work: The Promise of the New Digital Work Society. New York: McGraw Hill.

Grosse, C. U. (2002). Managing Communication within Virtual Intercultural Teams. Business Communication. Quarterly, 65, 22-38. Thunderbird, the American Graduate School of International Management. http://dx.doi.org/10.1177/108056990206500404

Hall, E. T. (1983). The Dance of Life. Garden City, NY, Anchor Press/Doubleday.

Hofstede, G. H. (1991). Cultures and Organizations: Software of the Mind. McGraw - Hill, London.

ICSC (International Civil Service Commission). (2001). A Framework for Human Resources Management. Two United Nations Plaza - 10th Floor, New York, NY 10017.

Keogh, J. (2013). International Teams: Beyond Cultural Differences. Keogh \& Associates Consulting, LLC. Retrieved from http://www.jackkeogh.com/

Lewis, C. (2006). Addressing Communication Issues When Managing Multicultural Teams. The Intercultural Consulting Group. Retrieved from http://www.luthais.com

Lewis, C. (2006). Managing and Working with Diverse Teams. The Intercultural Consulting Group. Retrieved from http://www.luthais.com 
Maureen, G. (1999). Communicating across Cultures. London: Palgrave Macmillan.

Miles, M. B., \& Huberman, A. M. (1984). Qualitative Data Analysis: A Sourcebook of New Methods. California; SAGE publications Inc.

Pnina Shachaf. (2008). Cultural Diversity and Information and Communication Technology Impacts on Global Virtual Teams: An exploratory study. Information and Management, Indiana University, Bloomington. http://dx.doi.org/10.1016/j.im.2007.12.003

\section{Copyrights}

Copyright for this article is retained by the author(s), with first publication rights granted to the journal.

This is an open-access article distributed under the terms and conditions of the Creative Commons Attribution license (http://creativecommons.org/licenses/by/3.0/). 